\title{
La joyería popular leonesa
}

Ya hace algunos años que hemos venido recogiendo documentación sobre la joyería popular de las comarcas leonesas, principalmente a través de los inventarios de bienes de los siglos XVIII y XIX que se conservan en el Archivo Histórico Provincial de León y, al mismo tiempo, hemos realizado una sosegada investigación de campo buscando las joyas populares que guardan las familias de los pueblos leoneses. Fruto de este trabajo fue ya, en parte, publicado en una monografía que trata de la indumentaria tradicional ${ }^{1}$. El tema hasta ahora ha sido muy poco estudiado. En 1987 apareció un libro sobre los plateros astorganos del siglo $\mathrm{XVII}^{2}$, que nos aporta documentación valiosa referente a las joyas que hacían algunos plateros de la ciudad de Astorga. El autor se centra en la vida y obra de once plateros, tres de ellos trabajan las joyas populares, alternando con la platería religiosa: Pedro González del Río, Manuel García y Juan Callejo. Estos tres plateros reciben encargos de las piezas de plata (alconciles y avellanas) y de los corales que forman las collaradas, regalo de donas o de dote para la novia, así como de los joyeles ${ }^{3}$, tablillas ${ }^{4}$, relicarios, medallas y cruces que colgaban de estos collares. Aún podemos admirar hermosas collaradas maragatas en el Museo de la Catedral de Astorga o en el Museo del Pueblo Español de Madrid ${ }^{5}$. Encontramos entre la docu-

1 La Indumentaria tradicional en las comarcas leonesas (León: Diputación de León, 1991), 526 pp., con 412 ilustraciones.

2 Fernando LlamazARes RodrígueZ, La Platería astorgana del siglo XVI a través de documentos del Archivo Histórico Provincial de León (León: Institución "Fray Bernardino de Sahagún", Diputación de León, 1987), 157 pp., con fotografías de platería religiosa: cruces, custodias e incensarios.

3 uun joyel y una tablilla de plata $=104$ reales", importe de la plata y hechura que el platero Manuel García hace para una vecina de Curillas, año 1707.

" "una tablilla de plata, unos bincos y tres sortijas $=93$ reales", que el platero Juan Callejo hace para un vecino de San Martín del Agostedo, año 1698; "una tablilla de plata, una cruz con sus arconciles y abellanas, y sortijas $=146$ reales", que le debía un vecino de Astorga al platero Pedro González del Río, año 1656.

5 Catálogo de la colección de collares (Madrid: Museo del Pueblo Español, s.a.), núms. 8.789 y 12.811 . 
mentación de estos tres plateros algunos ejemplos como éstos: "unas donas de plata y coral" valoradas en trescientos cincuenta y cinco reales, que el platero Juan Callejo hace para un vecino de Foncebadón, año 1698, o "unas donas de plata y echura de ellas" por doscientos veinticinco reales, para un vecino de Castrillo de los Polvazares, año 1693. Y en el inventario de los bienes que dejó Pedro González del Río, el artista astorgano más solicitado del siglo XVII y cuya obra estuvo centrada en la platería religiosa, según Fernando Llamazares ${ }^{6}$, podemos hallar algunos datos interesantes para el tema que nos ocupa ${ }^{7}$.

Astorga ha sido a lo largo de los siglos un centro destacado de la joyería popular. En los siglos XVIII y XIX el número de plateros activos en Astorga, que reciben encargos de joyería, aumenta considerablemente ${ }^{8}$.

\section{LAS JOYAS EN LOS INVENTARIOS DE BIENES: SIGLOS XVIII Y XIX}

Las más ricas y valiosas joyas están reseñadas en algunos inventarios de Maragatería y se refieren generalmente a las donas o regalos que hacía el novio a la novia, así: "unas Donas de maragata que pesan siette livras, en dos mil y diez y seis reales" o "treinta onzas de Joias, corales y relicarios enilados con sus gordones a estilo de las maragatas", cuyo precio se regula a quince reales la onza y suman cuatrocientos cincuenta reales ${ }^{9}$.

\section{Collares}

Las grandes collaradas maragatas están formadas por varias vueltas de corales y piezas de plata o de plata sobredorada: los alconciles, cilíndricos,

6 Cf. op. cit. en la nota 2, pp. 47-58.

7 "Treinta y nuebe abellanas de plata lisa [...] y veinte y una abellanas labradas [...] más catorce arconciles nuebos y dieciocho biexos [...] de peso zinco onças y media [...] más trece abellanas lisas que pesaron dos onças, doce pares de arrecadas grandes y pequeñas y siete bincos grandes y pequeños [...] tres moldes de remate de tablillas [...] dos onças y media de coral [...]". (A.H.P. León, año 1665, a 21 de junio). Cf. op. cit. en la nota 2, pp. 114-117.

8 Mi buen amigo Miguel Ángel González, antiguo Director del Archivo Diocesano de Astorga, me ha facilitado una lista de treinta y cuatro plateros activos en Astorga, en los siglos XVII y XIX, que reciben encargos de joyería. Y entre ellos está el apellido Ramos, siglo XIX, cuya marca aparece en pendientes o polcas que han llegado hasta nosotros. Astorga tenía a mediados del siglo XIX seiscientos treinta y cuatro vecinos. Cf. MADOZ, Dicc. Geogr., s.v.

9 En inventarios de principios del siglo XIX, años 1809 y 1806. 


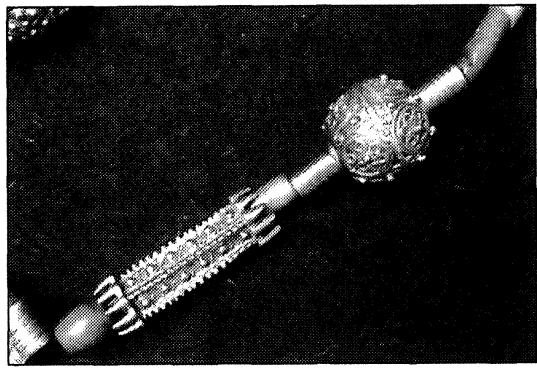

FIG. 1.-Alconciles y avellanas de la collarada maragata.

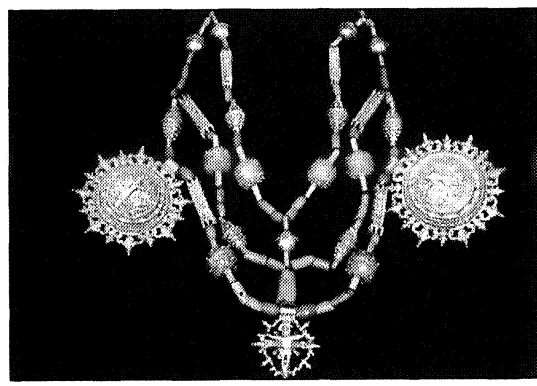

FIG. 2.-Collarada maragata (Madrid, Museo del Pueblo Español). y las avellanas, esféricas, y adornadas con joyeles, tablillas, medallas, cruces, relicarios o vidrieras. Las piezas de plata, que junto a los corales forman las vueltas de las collaradas: los alconciles y las avellanas se encuentran también en los collares del traje de boda o de vistas albercano (Salamanca). $\mathrm{Y}$ es interesante comparar las piezas de una y otra comarca, más afiligranados los alconciles salmantinos (denominados allí arconciles o carros). A veces, aparece en los collares maragatos alguna pieza bicónica, semejante a la que lleva el collaret ibicenco. Estas grandes collaradas entroncan con culturas muy antiguas. Si observamos las figurillas púnicas de Ibiza, o los collares que de esa época se conservan en los museos, vemos que sus formas y decoraciones son muy similares. También las damas ibéricas de Baza y de Elche presentan grandes collares con profusión de piezas colgantes. Pero es, sobre todo, en el período nazarí y entre los moriscos de Granada donde se documenta un collar árabe, el bayte 'alhaite', compuesto de piezas ensartadas tubulares, abellotadas o esféricas, y de otras colgantes de diversas formas, que ya Gómez Moreno relacionó con los que usaban "las maragatas astorganas y las charras salmantinas" ${ }^{10}$.

Muy expresivo es el texto que escribió Eduardo Saavedra, en la segunda mitad del siglo XIX, sobre los collares de las mujeres de Maragatería:

Dos clases principales de piezas, además de los famosos corales, componen estas collaradas: unas esféricas, como de una pulgada de diámetro, que llaman avellanas, y otras prismáticas, de unas dos pulgadas de largo y media de ancho, que denominan alconcillos ó alconciles (corrupción de alcorcíes); unas y otras son fundidas, de plata sobredorada, con una cantidad de metal considerable, y se colocan alternativamente en la sarta según su número y proporción. Entre ellos se intercalan dijes de coral ó piedras toscamente labradas, que hacen oficio de amuletos para enfermedades, cada uno según su color y sustancia, y colocan también un enorme disco sobre el pecho, ó tres, uno en el pecho y dos en los hombros, ó á

10 Cf. op. cit. en la nota 1, p. 418. 


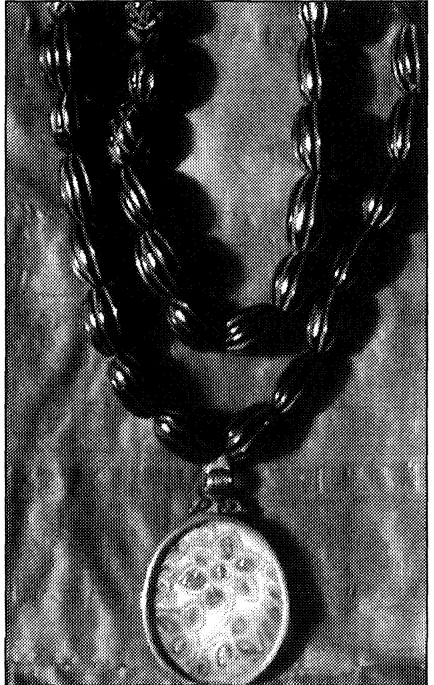

FIG. 3.-Collar de azabache (Astorga: Museo de los Caminos).

veces más, distribuidos con la posible simetría. Cuando los discos son de una plancha de metal fundido, ó de dos combadas que cierran una figura de lenteja, se llaman joyeles, llevan muchos adornos bastante bien cincelados, con bonitas cresterías en el borde, y en el centro un Crucifijo sumamente rudo. Otras veces forman un cuadro con cristal por un lado ó dos lados y malísimas estampas de devoción, ó bien medallones para encerrar reliquias; llamándose vidrieras en el primer caso, y relicarios en el otro. Este verdadero museo ensartado en fuertes hilos, se ciñe a la garganta, cayendo el resto por el pecho en una ó más vueltas; añaden con frecuencia un gran rosario de plata, que desde el cuello pende hasta las rodillas; y á tan diversas piezas acuden como Banco de economías, para venderlas á los plateros de Astorga en casos de apuro ${ }^{11}$.

Junto a las ricas collaradas, que poseían determinadas familias, aparecen en los inventarios de Maragatería otras más sencillas, también de corales y piezas de plata. Abundan mucho los Joyeles ${ }^{12}$, y es muy significativo el ejemplo que encontramos en el testamento de una vecina de Molinaferrera: "Ytem mando yo, la dicha Jerónima, a Nuestra Señora del Rosario desta villa de Molinaferrera, el Joiel grande de plata que tengo de mis donas", año 1740 . Se reseñan tablillas - medallas grandes con imagen religiosa grabada por ambos lados ${ }^{13}$ - cruces $^{14}$, vidrieras o relicarios ${ }^{15}$.

11 "La mujer en León" por Eduardo SAAVEDRA, en la obra de varios autores: Las mujeres españolas, portuguesas y americanas... (Madrid: Imprenta y Librería de D. Miguel Guijarro, 1873), en el Tomo II, pp. $75-77$ y 82 , se trata el traje y joyas de la mujer maragata.

12 "un joyel de plata que pesa quatro onzas escasas $=78$ reales" (Villalibre, 1783); "un joyel de plata, ahumado en oro, que pesa seis onzas $=120$ reales" (Lagunas de Somoza, 1783); un joyel de plata sobredorado $=100$ reales" (Morales, 1794); un joyel de plata $=79$ reales" (Lucillo, 1803); uun joyel, una tabrilla y una vidriera $=60$ reales" (Andiñuela, 1803).

13 En el comercio de José Calvo, en Rabanal del Camino, se hallaban empeñadas en el año 1739 hasta nueve tablillas de plata pertenecientes a vecinas de Andiñuela, Foncebadón, La Maluenga y Rabanal. (A.H.P. de León, Caja 10269). Y se hallan tablillas formando parte de los collares en ejemplos como éste: "una gargantilla con una tabrilla, tres alconziles de plata, beinte y siete corales, con una sarta que tiene dos caras $=100$ reales" (Val de San Lorenzo, 1801).

14 Cruces de Caravaca, de Santo Toribio y de "ánima" se nombran en inventarios de todas las comarcas leonesas.

15 "una joya o bidriera de plata $=30$ reales" (Molinaferrera, 1785); "una reliquia con su zerco de plata $=20$ reales" (Val de San Lorenzo, 1802); "un joyel, una tabrilla y 


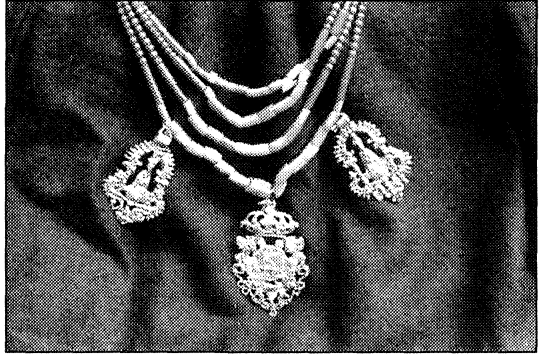

FIG. 4.-Collar de corales. San Esteban de Nogales (Valdería)

El azabache está presente, principalmente, en esos rosarios que a modo de gran collar vemos reflejados en grabados antiguos ${ }^{16}$, y que recogen los inventarios de Maragatería ${ }^{17}$. En nuestro recorrido por los pueblos de esta comarca hemos visto collares de azabache que guardaban las familias, y otros testimonios quedan en el Museo de los Caminos de Astorga.

Hay collares de corales en todas las comarcas leonesas y, en muchos casos, acompañados con alconciles y avellanas de plata. Podemos leer en inventarios de las Tierras bañezanas: "Las donas de la biuda se componen de una buelta de cincuenta y dos corales, seis alconciles, dos abillanas, una cruceta, todo de plata; unas arracadas de lo mismo" (San Feliz de la Valdería, 1794) ${ }^{18}$.

En las Riberas Altas del Órbigo los alconciles reciben el nombre de sueños: "unas bueltas de corales que se componen de seis abellanas, dos

una vidriera $=60$ reales" (Andiñuela, 1803); "un relicario con zerco de plata" (Molinaferrera, 1808).

16 Así en el grabado de M. Sutil, siglo XviII, que reproduce el P. Flórez, España Sagrada, XVI (Madrid, 1762), o en el grabado de A. Carretero, siglo XIX, sobre fotografía de J. Laurent, que publicó la Ilustración Española y Americana (1879), y en el mural de la Hispanic Society de New York, pintado por J. Sorolla en 1919.

17 "un rosario de Azebache negro con tres medallas de plata $=180$ reales" (Castrillo de los Polvazares, 1798); "un rosario de azebaches, grande $=21$ reales" (Santa Marina de Somoza); "un rosario de azebache, grande $=16$ reales" (Turienzo, 1810), etc. Además, encontramos amuletos de azabache en otras comarcas leonesas, como por ejemplo en las Riberas del Órbigo y Tierras bañezanas: "dos Ygas de azabache $=6$ reales" (Palacios de la Valduerna, 1793); "una Yga de zebache y dos caracoles chicos" (Quintana del Marco, 1796); "dos Ygas de azabache" (Benavides, 1800); "una sarta de azebache" (Castrocalbón, 1821), etc. Y ejemplos de azabache se ven en otras zonas de la provincia, así: "un azabache" (Grajal de Campos, 1799); "tres vueltas de corales con un azabache" (Villafrea, 1799); o "un rosario de azebaches redondos con su coral" (Bustos, 1783), etc.

18 Los ejemplos son numerosos, citaremos algunos: "Antonio Alonso le da a su mujer María Rubio, por razón de donas: un joyel, dos arrecadas, una buelta de corales con siete piezas de plata y unos bincos". Y como dote llevaba "unas arrecadas y una vidriera de plata" (Quintana del Marco, 1790); "una buelta de corales con sus piezas correspondientes de plata y un joyel de plata" (donas de Castrocontrigo, 1798). 


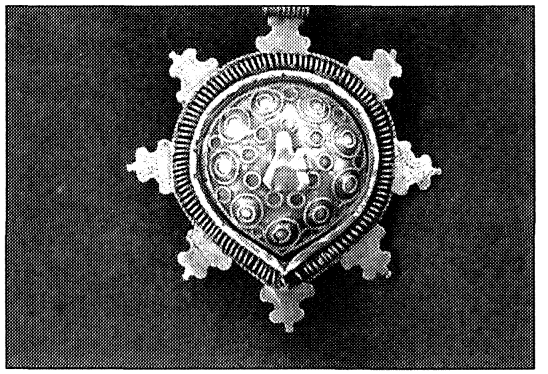

FIG. 5.-Joyel de Alija del Infantado (Bajo Órbigo).

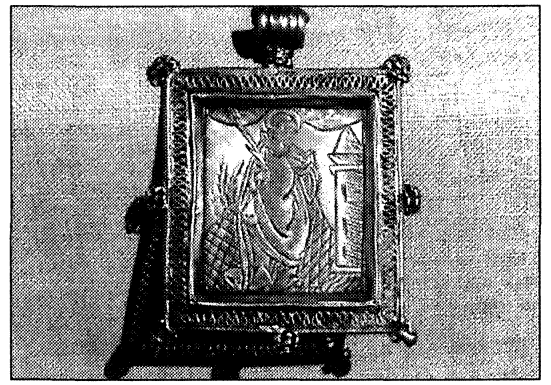

FIG. 6.-Tablilla (Maragatería).

sueños, una bidriera de plata y beinte y ocho corales medianos" (Benavides de Órbigo, 1802) ${ }^{19}$.

De estos collares colgaban, en ocasiones - como hemos visto en Maragatería- joyeles ${ }^{20}$, tablillas $^{21}$, relicarios o vidrieras ${ }^{22}$, cruces y me-

19 Otros ejemplos: "unas bueltas de corales que se componen de una cruz de plata y quatro abellanas y cuatro sueños y treynta y siete corales con sus granates y las arrecadas, que todo ello pesan siete onzas = 160 reales" (Villamor de Órbigo, 1799); "unas bueltas de corales con seis sueños, seis abellanas y su cruz, y cinquenta corales = 120 reales" (Benavides, 1800); "tres quarterones de plata y corales en diferentes piezas, en seis bueltas debedidas $=280$ reales" (Veguellina de Órbigo, 1802); "unas vueltas de corales grandes que se componen de una santa de plata, cuatro avellanas de plata grandes y seis medianas, con seis sueños y sesenta y tres corales grandes y chicos con sus granates, que todo ello pesó nueve onzas $=120$ reales" (Villamor de Órbigo, 1835), etc.

20 "un joiel y una cruzeta de plata $=70$ reales" (Ribas de Valduerna, 1788); "un joyel de plata $=52$ reales" (Castrocontrigo, 1795); "un joiel de plata sobredorada = 140 reales" (Destriana, 1796); "un joyel afeligranado, figura de corazón, de plata = 30 reales" (Quintana del Marco, 1796); "un joyel bueno de plata = 60 reales" (Castrocalbón, 1800); "un joyel dorado y un Agnus Dei de plata $=100$ reales" (Destriana, 1800); "un joyel de plata sobredorado $=40$ reales" (Villanueva de Valdejamuz, 1809), etc.

21 "una tablilla de plata $=32$ reales" (Huerga de Garavalles, 1786); "una tabrilla dorada de plata $=60$ reales" (Nogarejas, 1797); "una tablilla de plata $=40$ reales" (Benavides, 1800); "una tablilla de plata = 30 reales" (Castrocalbón, 1800); "una tablilla o joel sobredorado $=55$ reales" (Castrocalbón, 1803); "una tablilla de plata algo dora$\mathrm{da}=33$ reales" (Castrocalbón, 1820), etc.

22 "una reliquia con cerco de plata $=12$ reales" (Saludes del Páramo, 1808); "tres vidrieras de plata $=32$ reales" (Pobladura de la Valdería, 1804); "una vidriera de plata = 12 reales" (Benavides, 1800); "una vidriera grande con cerco de plata $=12$ reales" (Navianos, 1800), etc. A veces aparece una vidriera o relicario para colgar con una cinta al cuello: "una vidriera con su cinta $=14$ reales" (dote, Jiménez de Jamuz, 1782); "una vidriera con su cinta $=36$ reales" (Alija del Infantado, 1806); "una reliquia con su cerco de acero y una cinta de seda $=10$ reales $^{n}$ (Destriana, 1794). 


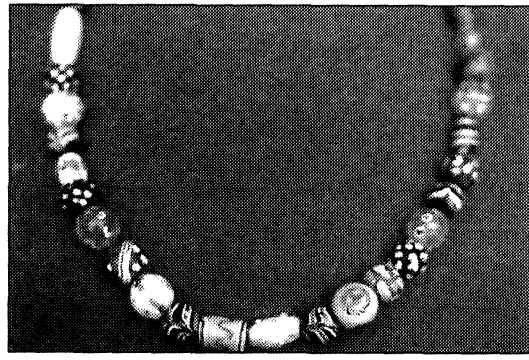

FIG. 7.-Collar de cuentas de pasta vítrea (Riberas del Órbigo).

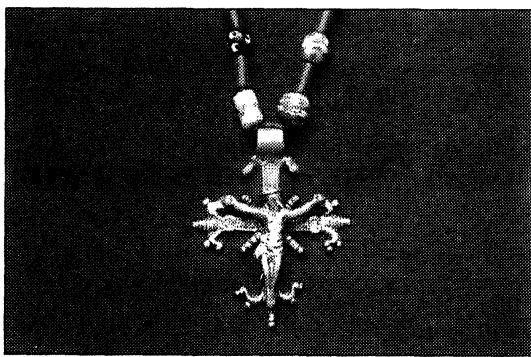

FIG. 8.-Cruz en un collar (Valdería)

dallas ${ }^{23}$. Otras veces, las vueltas de corales se adornaban con una simple cruz o con una medalla. Se recogen en esta zona, quizá más que en otras, citas de agnusdéi de plata o de plata sobredorada, imagen muy valorada por la religiosidad popu$\operatorname{lar}{ }^{24}$. En pueblos del Alto Órbigo conservan todavía, como un regalo que se le hacía a la novia, una especie de joyel o vidriera que llaman "el jardín" 25 .

Seguimos encontrando el coral en collares de la Montaña y en el resto de las comarcas leonesas, aunque no con tanta frecuencia ni en general tan valorados en los inventarios como los de Maragatería, Riberas del Órbigo y Tierras bañezanas ${ }^{26}$. Otro tipo de gargantilla o collar muy generalizado por toda la geografía leonesa es el de "sartas de piedra" (pasta vítrea) en varios colores. Sin embargo, en los inventarios las citas son escasas ${ }^{27}$. En algunos

23 Cuando se reseña la advocación de la medalla, en ésta o en otras comarcas leonesas las más frecuentes son: Nuestra Señora de Nieva, del Sagrario de Toledo, del Pilar, Virgen de la Peña, de las Ermitas, del Camino. Y entre los santos: San Benito, San Bernardo, Santiago, San Francisco, Santa Catalina, Santa Bárbara y Santa Teresa.

2i En la comarca de la Valduerna: "un Agnus Dei de plata sobredorada $=30$ reales" (Destriana, 1796); "un Agnus Dei de plata = 40 reales" (Destriana, 1799); "un Agnus Dei de plata $=40$ reales" (Destriana, 1809), etc. También en la montaña de Riaño: "un Agnusdey de plata $=24$ reales" (Boca de Huérgano, 1783).

.25 En el pueblo de Velilla de la Reina aún hoy recuerdan y conservan "el jardín", como regalo de boda. En un inventario de Astorga, 1799, aparecen como dote: uun jardín de el cuello con su zerco dorado $=20$ reales, otro jardín con piedras blancas $=10$ reales".

26 Citaremos algunos ejemplos de la Montaña: "dos vueltas de corales con seis piezas de plata $=18$ reales" (Villafeliz de Babia, 1804); "Seis vueltas de corales con diez y nuebe piezas de plata chicas = 97 reales" (Caboalles de Abajo, 1799); "dos bueltas de corales $=4$ reales" (Villafrea, 1813); "una cruz con su buelta de corales finos, una abillaneta y un ángel todo de plata $=10$ reales" (Camposalinas, 1833), etc.

27 En un comercio de Astorga había en el primer tercio del pasado siglo, entre otras cosas: "veinte y ocho collares de vidrio, a dos reales cada uno $=56$ reales; dos 
lugares suelen adornarlos con una cruz o cruceta de plata o con una medalla. A estos collares se refiere el escritor del siglo XIX, Eduardo Saavedra, al describir el atuendo de las mujeres de Babia: "no adornan el cuello sino pobres sartas o cuentas de vidrio de diversos colores, con crucecita de plata" ${ }^{28}$. Y más recientemente, Carlos Piñel hacía un acertado comentario sobre estos collares de cuentas polícromas, que solían ser de un color base - blanco, negro, azul- y salpicadas con pequeños puntos de diversos colores, en bello contraste. Se difundieron por todo el norte de Zamora y el Aliste, y guardan semejanza - dice él- con culturas muy antiguas:

\begin{abstract}
La cercana relación de estas cuentas, con piezas similares del mundo Tartésico y Fenicio-Púnico, vendría a confirmar una vez más la cada vez más clara teoría de su posible pervivencia en nuestras comarcas occidentales, igual que sucede con algunos aspectos concretos del bordado y sus elementos decorativos [...] Su vía de penetración unida al intenso comercio de los metales, por la Ruta llamada después de La Plata, de sur a norte, ya desde los siglos vil y VI antes de Cristo, contrastada con los numerosos hallazgos arqueológicos, nos hace pensar que, a pesar del largo lapso de tiempo transcurrido, permanecen aún en determinados lugares pervivencias y gustos de muy antiguo origen, que aún se han mantenido hasta nuestros días. Añadiré que personalmente he recogido cuentas de vidrio, con gran similitud a las descritas, en yacimientos arqueológicos de la provincia de Salamanca, junto con materiales que nos permiten fecharlas con total seguridad entre los siglos VII y VI antes de Cristo ${ }^{29}$.
\end{abstract}

\title{
Amuletos
}

Las higas de azabache o de coral colgaban a veces de los collares de las mujeres o de los dijeros de los niños ${ }^{30}$. En los inventarios se recogen, además, otros amuletos muy significativos, como eran las llamadas "piedras de leche": "una cuenta de leche, una medalla de Nuestra Señora de Nieva... una higa de hasta de cierbo con su engacito en plata" (Villamañán, 1798). Y junto a las "piedras de leche", ágatas blanquecinas que la mujer colgaba cerca de los pechos para facilitar la lactancia del niño, están las

collares de similor, a veinte reales $=40$ reales; diez y ocho collares granates y perlas falsas a dos reales cada uno $=36$ reales... (Inventario por fallecimiento del comerciante, año 1818).

28 Cf. op. cit. en la nota 1, pp. 79-80.

29 Cf. Carlos PIÑEL, La Zamora que se va. Colección de Etnografía CastellanoLeonesa de Caja España (Zamora, 1993), pp. 246-249.

30 Véanse ejemplos en la nota 17. 
"piedras de sangre", ágatas de tono rojizo que llevaba contra los flujos de sangre y, con el mismo fin, "la cornalinaw: "una cornalina engazada en plata" (Castrocalbón, 1829) o "una cornalina de sangre" (Urdiales del Páramo, 1754), y "una piedra de sangre" (Palacios de la Valduerna, 1793).

Vemos también reseñada la venturina, utilizada contra el mal de ojo: "una piedra venturina" (Molinaferrera, 1808) o "una sarta para quitar calenturas" valorada en cuarenta reales (Val de San Lorenzo, 1802).

Amuletos son las puntas de asta de ciervo: «una punta de asta de zierbo engastada en plata" (Castrocalbón, 1820); o "un cuerno de zierbo embutido en platan (Boca de Huérgano, 1784) que se usaba como defensa contra animales ponzoñosos y contra el mal de ojo; y, la cabeza de víbora, contra la erisipela: "una cabeza de vibora con su engastonadura de plata" (La Bañeza, 1800). Las cruces de Caravaca, que abundan en los inventarios, fueron en cierto modo unos amuletos muy apreciados por las mujeres en el momento del parto y como protección del fuego, la rabia y el rayo ${ }^{31}$.

Pero quizá lo más significativo de una mentalidad muy extendida en otras épocas sean los dijes o amuletos que se ponían a los niños, junto a los Evangelios y la Regla de San Benito, para protegerles de los males que les acechaban y de posibles enfermedades, al mismo tiempo que beneficiaban la actividad de sus sentidos, sobre todo el oído y el habla. Daremos dos ejemplos que hemos seleccionado entre otros varios: «un aderezo para niños que se compone de campanilla de plata, un pie de tejón engarzado en plata, un chupador engarzado en lo mismo con dos corazones de seda también engarzados en plata", valorado en cuarenta y cuatro reales (Cubillos del Sil, 1792); aunos dijes de niño compuestos de una campanilla con su cadena, un diente, una castaña de yndias, un chupón con tres cascabeles y engastonado en plata, un relicario con su engastonadura afeligranada y de plata", valorados en ciento sesenta reales (La Bañeza, 1800).

\section{Pendientes}

Cuando la poetisa escocesa Jane Leck pasó por tierras leonesas en 1883 llamaron su atención los grandes pendientes que llevaban algunas mujeres de los pueblos, aunque era difícil poder admirar estas joyas -escribe ella- porque quedaban medio ocultas bajo el pañuelo. Pensó que habrían sido legados de madres a hijas durante generaciones. Su sorpresa

31 Puede consultarse el Catálogo de amuletos del Museo del Pueblo Español por Concepción ALARCón ROMÁN (Madrid, 1987), con bibliografía sobre el tema. 
fue, cuando en la estación de Ponferrada vio a una aldeana con esos pendientes, que le parecieron particularmente antiguos, y al preguntarle por ellos quedó algo desilusionada, podían comprarse - le dijo la mujer- en cualquier platería local ${ }^{32}$.

En nuestro recorrido por las comarcas hemos visto varios tipos de pendientes tradicionales, que podríamos quizá resumir en los siguientes grupos: los grandes aros con colgante triangular y plano; los pendientes circulares, llamados generalmente arracadas; las calabazas y las polcas.

De esos grandes aros con colgante triangular y plano que reflejaron grabadores del siglo XIX ${ }^{33}$, quedan ejemplares en pueblos de la Montaña, la Ribera y Maragatería ${ }^{34}$. En el Museo del Pueblo Español de Madrid hay una buena colección procedente de la zona de Astorga. Según Carmen Baroja de Caro:

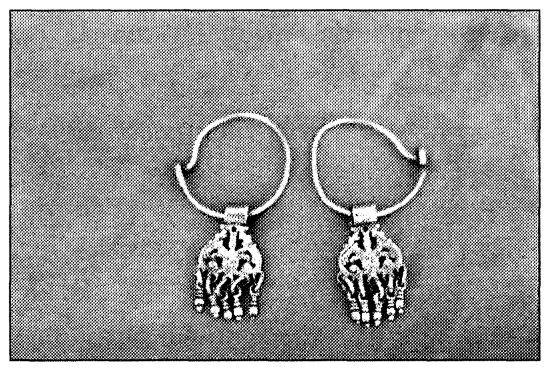

FIG. 9.-Aro con colgante triangular. Los Argüellos (Montaña Central).
Estos aros, generalmente usados por las mujeres de las provincias leonesas y algo en Asturias, son de plata, bronce y hasta de hierro; su tamaño varía de cuatro a ocho centímetros de diámetro y suelen llevar un colgante laminar en forma triangular, decorado con hilos y bolas de filigrana o con trabajos calados de buril. El colgante va pasado por el aro mediante una ancha anilla fija estriada, y de él penden, mediante pequeñas anillas, cinco colgantitos alargados. Fácilmente se percibe el aire arábigo de estas piezas; la figura de mano extendida con sus cinco dedos es por de más significativa ${ }^{35}$.

Los pendientes circulares que llaman arracadas, son de un sólo cuerpo en forma de aro plano; en el espacio interior, muchas veces, un col-

32 Cf. Concha CaSAdo lobato y Antonio CarReira VéREz, Viajeros por León. Siglos XII-XIX (León: Santiago García editor, 1985), p. 238.

33 En el grabado de A. Carretero, dibujo de J. Cuevas, "Aldeanos de las inmediaciones de la Bañeza" vemos a la mujer con pendientes de grandes aros (La Ilustración Española y Americana, 1875). Cf. op. cit. en la nota 1, p. 229.

34 Nieves DE HOYOS denomina "gallegos" a este tipo de pendientes, que le hacen recordar las arracadas fenicias del tesoro de Cádiz y de Aliseda, cf. "Orfebrería popular española. Tipos de pendientes regionales. La colección Gordón", en Arte Español, XIII, 1941, p. 29.

35 Cf. Catálogo de la colección de pendientes (Madrid: Museo del Pueblo Español), s.a., p. 8. Se reseñan en este Catálogo seis ejemplares: números 1.817, 1.821, 1.822, $1.833,7.365$ y 7.366 ; se dan fotografías de los números 1.817 y 1.833 . 


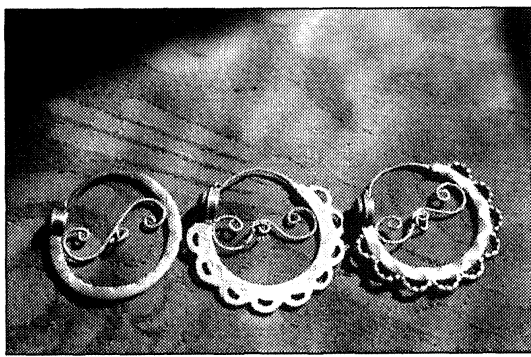

FIG. 10.-Arracadas de Omaña.

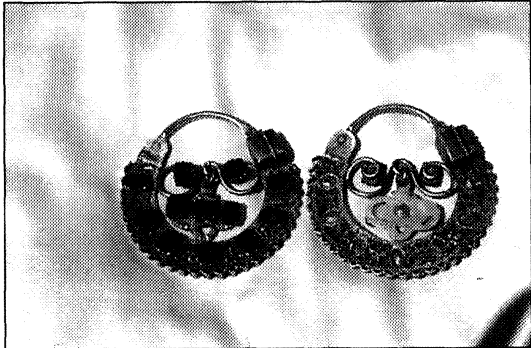

FIG. 11.-Arracadas de Valduerna.

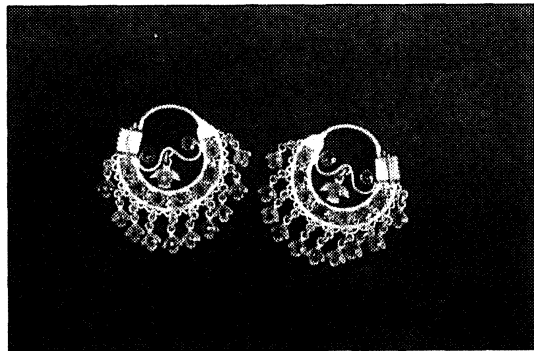

FIG. 12. Arracadas de Valdería.

gante en forma de paloma. Cierre de charnela y anilla soldada a un cuerpo con piedra verde o encarna$\mathrm{da}$, engastada comunmente con garras. Este modelo suele enriquecerse en las Riberas del Órbigo y Tierras bañezanas con piedras encarnadas y verdes e incluso colgantitos de piedras bordeando el aro, los hay de plata y sobredorados. En la zona de Astorga hallamos también la más reciente muestra de este antiguo modelo: son unos pendientes de tamaño más pequeño, en oro bajo y con topacio ${ }^{36}$.

Las calabazas son de dos cuerpos: el primero es un aro y el segundo está formado por dos esferas de distinto tamaño en filigrana, unidas por una pieza tubular. La esfera inferior se remata con pequeños colgantes, generalmente palomitas. Son los pendientes más valorados hoy por el pueblo, y destacan especialmente en las Riberas del Órbigo y comarcas bañezanas. Ya en el siglo XIX, Eduardo Saavedra comentaba el gusto de las mujeres de la Ribera por las joyas: "Tienen, como las maragatas, pasión por las joyas de gran tamaño; sólo que en lugar de las arracadas llevan, después de casarse, pendientes de plata sobredorada en forma de esferas con colgantes, que llaman calabazas, cuyo interior forran de seda carmesí para que resalten los calados" ${ }^{37}$. Se encuentran calabazas de plata y sobredoradas, en diversos tamaños. Algún ejemplar podemos ver aún en la mayoría de las comarcas.

Las polcas tienen uno y dos cuerpos planos con piedras engastadas verdes y rojas, también violáceas o blancas, y terminan en colgantitos o

36 Un conjunto de éstos y otros pendientes, están expuestos en el Museo de los Caminos en Astorga.

37 Cf. op. cit. en la nota 11 , pp. $80-81$. 


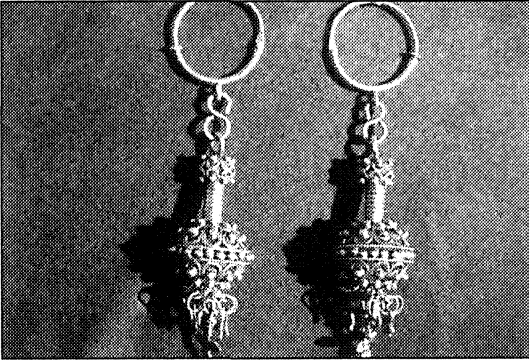

FIG. 13.-Calabazas (Alto Órbigo).

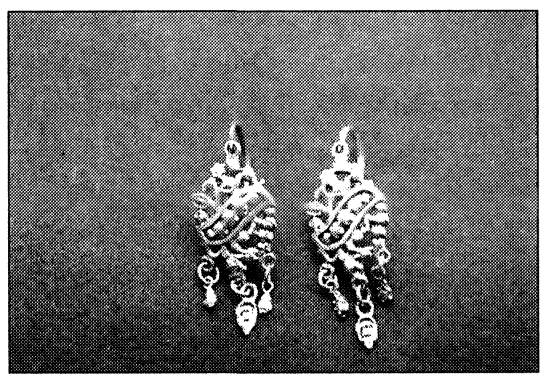

FIG. 14.-Polcas (El Bierzo).

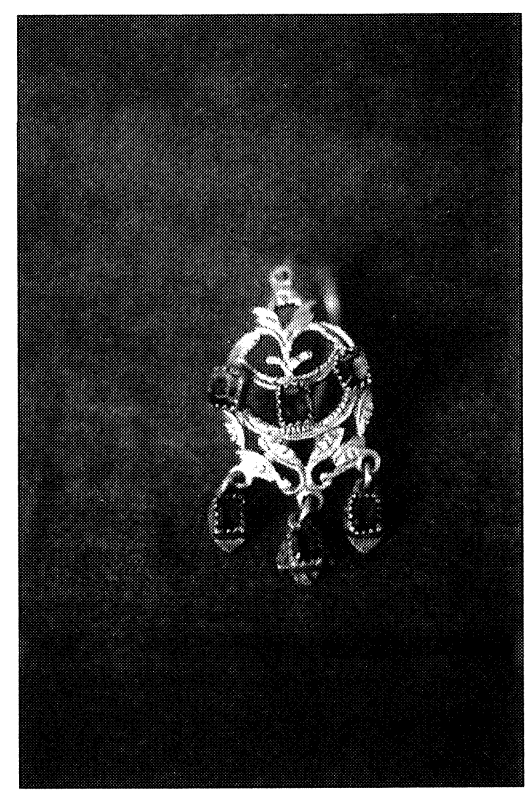

FIG. 15.-Polcas de Carrizo de la Ribera (Alto Órbigo).

goteras (a algunas polcas de un sólo cuerpo y redondeadas se las conoce con el nombre de rosetas). Existe una gran variedad de polcas y las hay que no llevan piedras.

En los inventarios se registran: $\operatorname{arracadas}^{38}$, vincos ${ }^{39}$, almendrillas ${ }^{40}$ (solamente en inventarios de la Valduerna) y, rara vez, arillos ${ }^{41}$, candadi$\operatorname{llos}^{42}$ y alcordes ${ }^{43}$.

38 "unas arrecadas de plata $=6$ reales" (Liegos, 1792); "unas arrecadas $=20$ reales" (dote, Felechares, 1800); "un par de arrecadas de plata $=20$ reales" (San Juan de Torres, 1802); "unas arrecadas con sus vincos de plata $=32$ reales" (donas, Benavides, 1802); "unas arracadas de plata, de donas $=20$ reales" (Altobar, 1804); "unas arracadas doradas $=60$ reales" (Astorga, 1830), etc.

39 "unos vincos de plata y unas arrecadas $=34$ reales" (Bustos, 1783); "unos vincos de plata para las orejas $=12$ reales" (Villanueva de Valdejamuz, 1790); "unos vincos de plata $=15$ reales" (Villalibre, 1809), etc. El vinco era el aro del pendiente, y podía ser el pendiente mismo, ya que había vincos, o sea pendientes, formados por un simple aro.

40 "dos almendrillas de plata $=24$ reales" (Destriana, 1796); "unas almendrillas con sus vincos de plata $=30$ reales" (Destriana, 1799); "unas almendrillas de plata, sobredoradas, con dos anillos $=40$ reales" (Destriana, 1800); "unas almendrillas con sus vincos $=30$ reales, otras almendrillas de plata $=10$ reales" (Destriana, 1804); "unas almendrillas y dos anillos dorados $=18$ reales" (Destriana, 1809), etc.

41 "unos arillos de plata" (Lucillo, 1783).

42 "unos candadillos de plata para las orejas $=6$ reales" (Astorga, 1802).

43 "unos alcordes con seis perillas $=44$ reales" (Castrocalbón, 1796). 
Con el nombre de arracadas se esconden sin duda varios tipos de pendientes, ya que vemos entre multitud de ejemplos como éste: «un par de arracadas de platan, otros que dicen uun par de arracadas de plata, con humo de oro, con cinco perillas cada una" o "dos arracadas con campanillos $\mathrm{y}$ arillos de plata" $\mathrm{y}$ "unas arracadas con sus vincos de plata". Las arracadas o pendientes eran también muchas veces regalo de donas, y como sugiere el Diccionario de Autoridades "pudo decirse de arras, por ser uno de los dones que daba el desposado a la esposan.

Pocas joyas populares más se nombran en los inventarios, a no ser anillos y sortijas ${ }^{44} \mathrm{o}$ hebillas y broches de plata.

CONCHA CASADO LOBATO

Departamento de Antropología Instituto de Filología. CSIC

A través de los inventarios de bienes de los siglos XVIII y XIX, principalmente, se estudia la joyería popular leonesa, atendiendo de manera particular a los collares, los amuletos y los pendientes. El estudio documental se contrasta y enriquece con el análisis de los ejemplares que se conservan entre las familias, en las diversas comarcas, o exponen en museos y colecciones.

Following a research on inventories from the 18th and the 19th centuries, the author discusses the folk jewellery of Leon province, in Spain; particularly necklaces, amulets, and earrings. In her discussion, the study of the written material appears enriched by, and in contrast to, the analysis of pieces owned by families living in the several areas of the province, or exhibited in museums and collections of other institutions.

${ }_{44}$ "dos anillos de plata $=12$ reales" (Villalibre, 1783); "dos sortijas de plata $=4$ reales" (Castrocalbón, 1800); "dos anillos de plata $=4$ reales" (Mena de Cilleros, 1804); "dos anillos dorados $=7$ reales" (Destriana, 1804); "un anillo de plata $=2$ reales" (Santa Marina del Rey, 1825); "dos anillos con sus piedras" (Navianos, 1827), etc. 